\title{
A Fixed Platform Topside Piping System Strength Analysis Under Dynamic Pigging/Slugging Loads
}

\author{
Zhongwei Li ${ }^{1}$, * Heng Gu ${ }^{2}$ \\ ${ }^{1}$ Department of Naval Architecture and Marine Engineering, University of New Orleans, New Orleans, LA, USA \\ ${ }^{2}$ Rexa Inc, West Bridgewater, MA, USA
}

Email address:

Zli9@uno.edu (Zhongwei Li)

${ }^{*}$ Corresponding author

\section{To cite this article:}

Zhongwei Li, Heng Gu. A Fixed Platform Topside Piping System Strength Analysis Under Dynamic Pigging/Slugging Loads. American Journal of Civil Engineering. Vol. 4, No. 5, 2016, pp. 216-224. doi: 10.11648/j.ajce.20160405.12

Received: June 12, 2016; Accepted: July 16, 2016; Published: July 19, 2016

\begin{abstract}
This paper presents the strength analysis of a fixed platform topside piping system under dynamic pigging/slugging load. Flow assurance analysis by using OLGA provided the flow history in each pipe. Then the dynamic loads at each pipe elbow were added by time sequence onto ANSYS model. The analysis has shown overstressed region under new pigging/slugging loads and proposed modification plan to reduce the stress.
\end{abstract}

Keywords: Fixed Platform Topside, Piping, Pigging, Slugging, Dynamic Load, Flow Assurance, Finite Element Analysis

\section{Introduction}

Pigging operations are required from the fixed platform topside piping operations. The pigging generated slugs boarding the platform may cause piping vibrations when they flow through the bends.

There have been various studies on pipe vibration during operation including pigging/slugging process. Direct measurement of the vibration is costly and restricted (Maekawa, 2014). CFD analysis is also very difficult (Xiao, 2015). Numerical analysis (Persson, 2015) is reliable and easier to achieve than analytical solution (Santos, 2015). Therefore FEA is a suitable tool for pipe vibration analysis during pigging/slugging process.

Computer aided simulation has been widely adopted in various field like energy (Cai, 2013), material (Zhang, 2015), physics (Liu, 2016), structural strength (He, 2016), fatigue (Zhang, 2013) and crack (Zhang, 2014).

Structural strength is important for engineering system. There has been intensive research for aluminum (Zhang, 2009), polymer (Wang, 2015) and composite (Liu, 2014).

The mechanical forces on the piping were analyzed consistent with BP document GP 41-20 "Design for Multiphase Flow", with forces applied from a dynamic simulation of the pigging slugging from Olga Simulations at 1-second data intervals for the critical slugging period.

Based on the analysis, piping modifications consisting of the addition of two braces to the Mahogany B piping have been recommended.

As the detailed fluid hold-up varied during the simulation, and coupling between fluid and the piping could not be assessed with OLGA and ANSYS Mechanical due to model limitations, the overall fluid density was changed from $10 \%$ to $90 \%$ in the ANSYS Mechanical finite element model analysis and the change in the response was analyzed.

The natural response of the system showed the higher fluid density reduced the system piping stress. As the final design is predicted to be safe with minimal fluid mass in the pipe, the conclusion is the piping will be adequate to overcome the excessive stresses for pigging runs regardless of liquid hold up at a recommended flow rate of $2 \mathrm{~m} / \mathrm{s}$ (150 MM scfd pigging gas rate), providing the recommended modifications are made.

\section{Flow Assurance Study}

\subsection{Purpose}

Flow assurance analysis performed the activities listed below:

Prepare a schematic of the piping configuration and incorporate the data into an OLGA model of the topsides 
piping system potentially associated with routine pigging. The piping was converted to equivalent hydraulic lengths to account for frictional loss and predict flow rates through the flow split around the separator using equivalent length values from API 14E, "Recommended Practice for Design of Offshore Piping Systems” 1991 Ed.

Determine the pressure, liquid velocity and liquid/gas density profiles for the platform topsides pipework during the pigging operation.

Run pigging operation simulations for three flow scenarios: 100MMscfd, 150MMscfd and 300MMscfd.

Identify maximum liquid velocity in the topsides piping during the pigging operation.

Provide velocity, density and time profile data to piping engineers for stress analysis.

\subsection{Details}

The key objective initially identified was to determine the maximum velocity / force that the topsides piping would have to withstand during the pigging operation.

Subsequently, after feedback from the piping engineers, dynamic profiles were supplied to allow dynamic analysis of the piping response by rerunning the simulation of the 150 MMscfd case for the 10 minute period with maximum fluid velocities in 1 second intervals.

A schematic of the OLGA model is shown in Figure 1.

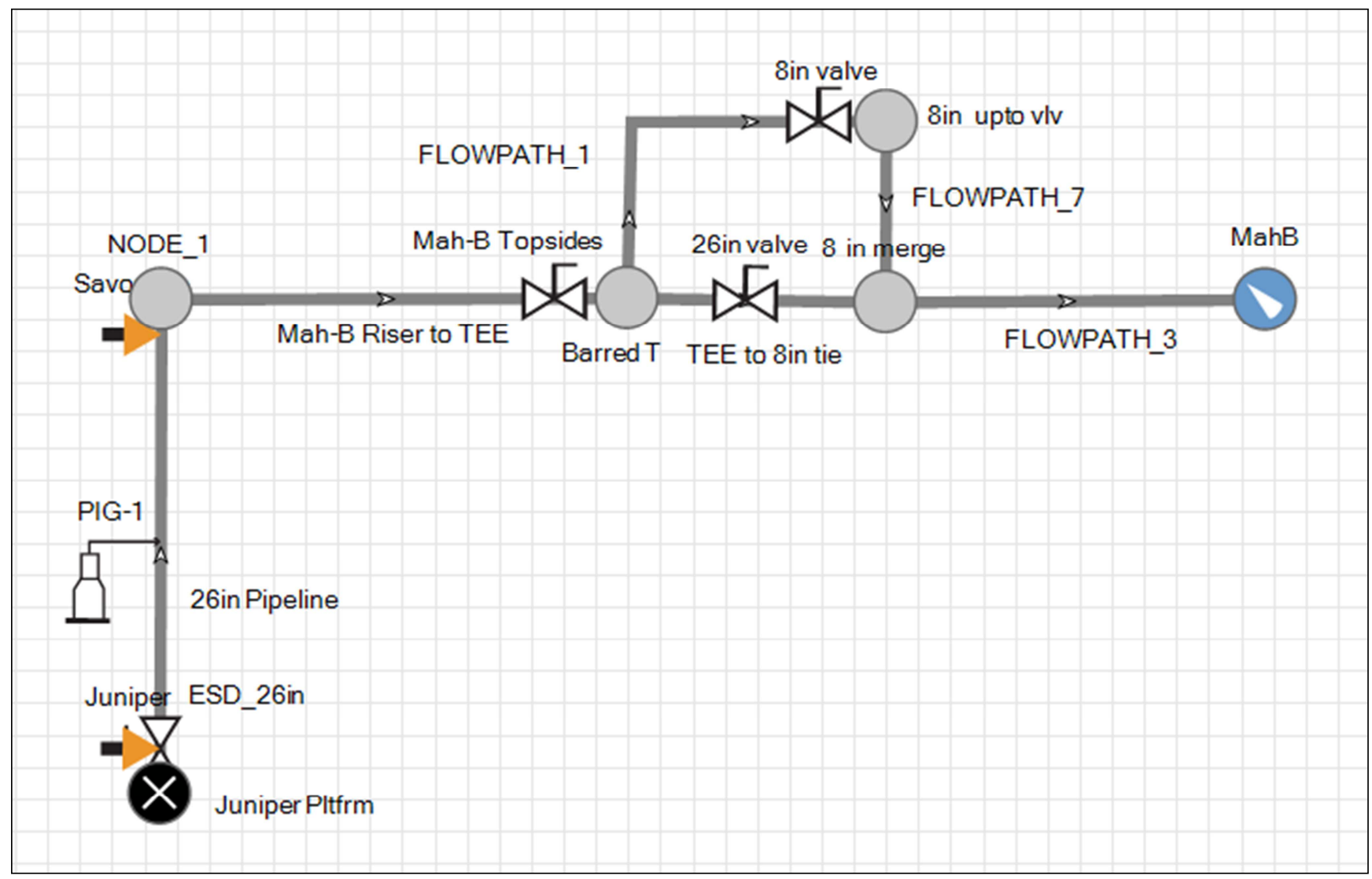

Figure 1. Flow Assurance Model.

The method in the GP was to determine maximum forces at bends, elbows, etc, using the equation (1).

$$
F_{S}=I_{F} \sqrt{2}\left(\rho_{s}-\rho_{g}\right) V_{m}^{2} A
$$

Where

$\mathrm{F}_{\mathrm{S}}=$ Force on pipe bend, Newtons

$\mathrm{I}_{\mathrm{F}}=$ Ratio of initial and final impulse forces to steady force, given the value of 2

$\mathrm{s}=$ Slug density, $\mathrm{kg} / \mathrm{m}^{3}$

$\mathrm{g}=$ Gas density, $\mathrm{kg} / \mathrm{m}^{3}$

$\mathrm{V}_{\mathrm{m}}=$ Mixed phase Velocity $\mathrm{m} / \mathrm{s}$

$\mathrm{A}=$ cross sectional area of pipe

The liquid slug was assumed to be water, and the gas was natural gas based on operational flow assurance simulations

\section{Structural Analysis}

\subsection{Material}

Carbon steel A106B/API-5L-B is the material used for the pipe work with Young's modulus of 2.07E11 MPa and Poisson's ratio of 0.3 .

For carbon steel A106 B, the yield stress is $241.3 \mathrm{MPa}$ (35, $000 \mathrm{psi})$ and the allowable stress is $137.9 \mathrm{MPa}(20,000 \mathrm{psi})$ according to ASME B31.3. For some pipes in accordance with ASME B31.8, the allowable stress for carbon steel A106 $\mathrm{B}$ is $217.2 \mathrm{MPa}$. 


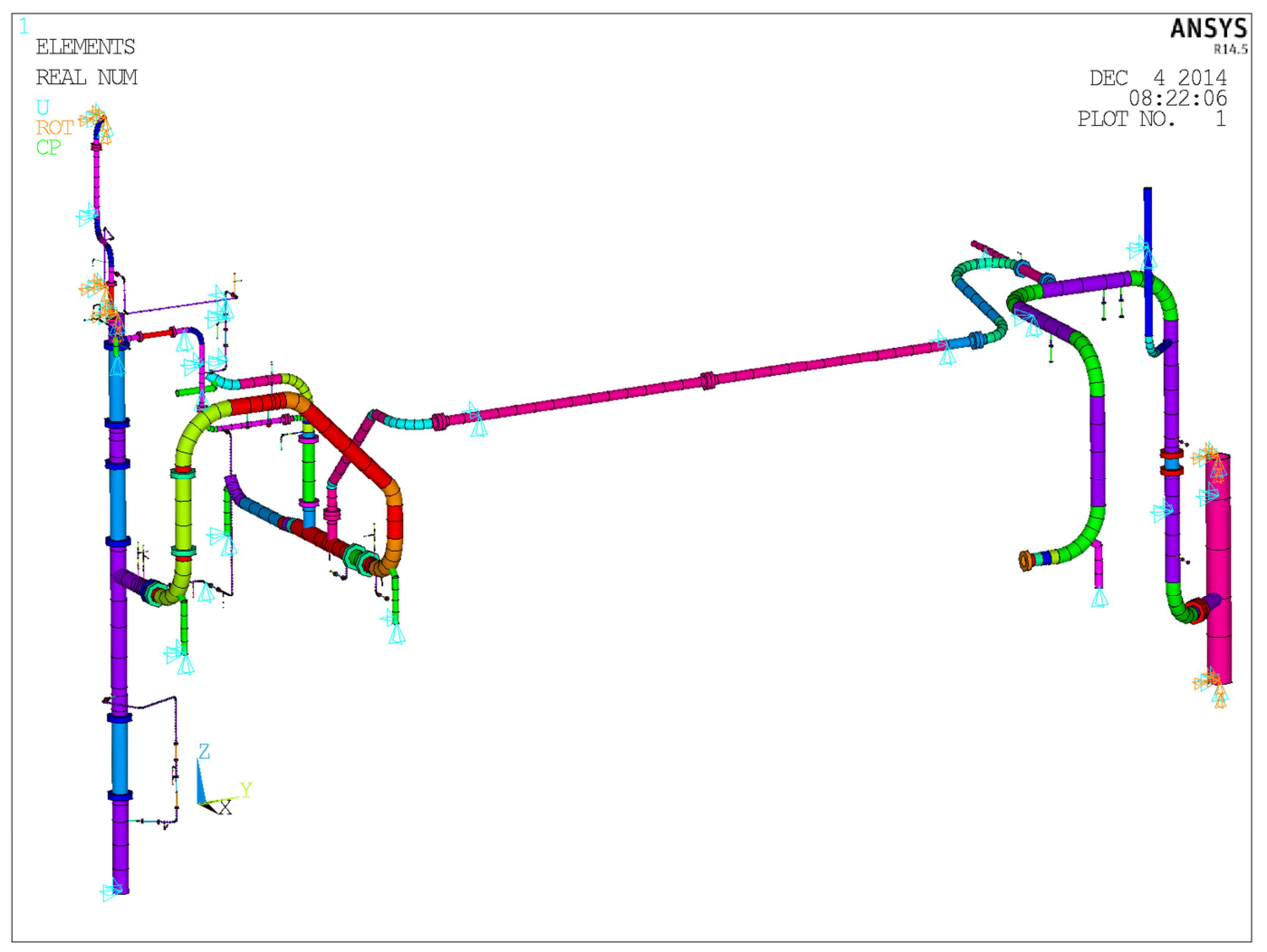

Figure 2. Piping System ANSYS Model.

\subsection{Boundary Conditions of FE Analysis - Pipe Support}

Pipe supports are in accordance with construction isometric drawings and Fluor Specification for Piping Standard Details FBPS-65-PI-03. Figure 2 displays the restraints applied on the ANSYS FE model. The blue colored supports provide translational restrictions, while the orange colored supports provide rotational restrictions.

\subsection{Structural Model}

The ANSYS model of the piping system is shown in Figure 2.

\subsection{Structural Loads}

Flow assurance provided the gas and liquid velocity along pipe length of Case 2 (150 MMScfd average pigging rate) at 1 second-intervals. Only the data from the time period with maximum velocities have been used because the peak velocities are significantly higher than the velocities outside of this time period. The maximum velocities of different pipes are listed in Table 1.

Table 1. Slug Flow Peak Velocity.

\begin{tabular}{llll}
\hline Line Number & Line Size (inch) & Density $\left(\mathbf{K g} / \mathbf{m}^{3}\right)$ & Velocity $(\mathbf{m} / \mathbf{s})$ \\
\hline 1100 & 26 & 1000 & 8 \\
1102 & 26 & 1000 & 8 \\
1103 & 20 & N/A & N/A \\
1106 & 16 & 1000 & 42 \\
1107 & 8 & 1000 & 9 \\
1028 & 24 & 1000 & 10 \\
\hline
\end{tabular}

The forces on bends and tees due to slug flow can be calculated by Equation (1).

Notice that the maximum fluid velocity, presented in Table 1, doesn't always appear at pipe bend location. The fluid velocity also changes with time. The forces on bends and tees are calculated based on the time history of fluid velocity including the local maximum velocity at that location.

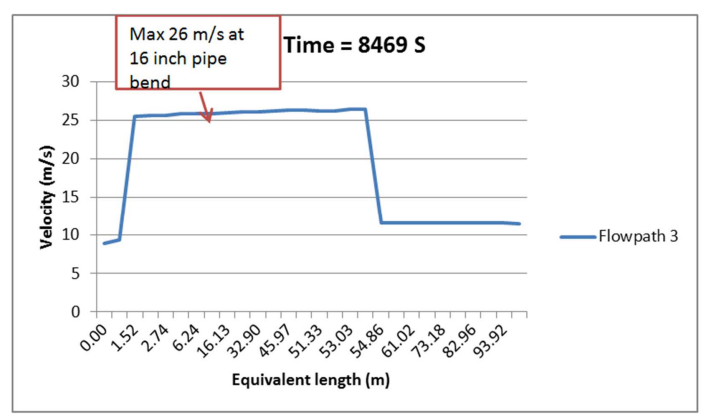

Figure 3. Fluid velocity in flowpath 3 at 8469 s.

The maximum flow was predicted to occur within the entrance of 16 inch diameter pipe that was downstream of a 26 inch diameter segment for the fluid. Figure 3 and Figure 4 show the fluid velocity along the equivalent length of this flowpath 3 (including 26 inch, followed by the 16 inch and the 24 inch pipes) at time point $8469 \mathrm{~s}$ and $8475 \mathrm{~s}$ respectively. Although the maximum velocity is $42 \mathrm{~m} / \mathrm{s}$ when time is $8475 \mathrm{~s}$, the location of the maximum velocity is not at a pipe bend. The maximum velocity at the 16 inch pipe bend location is $26 \mathrm{~m} / \mathrm{s}$ when time is $8469 \mathrm{~s}$. 


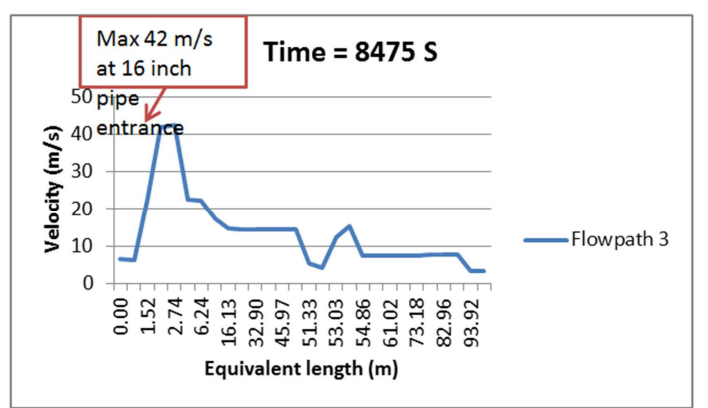

Figure 4. Fluid velocity in flowpath 3 at 8475 s.

Figure 5 shows the fluid velocity time history at that 16 inch pipe bend. It can be seen that the maximum velocity is $26 \mathrm{~m} / \mathrm{s}$ at $8469 \mathrm{~s}$. Correspondingly, the maximum slug force at the bend is also at $8469 \mathrm{~s}$ and is calculated by the fluid velocity of $26 \mathrm{~m} / \mathrm{s}$.

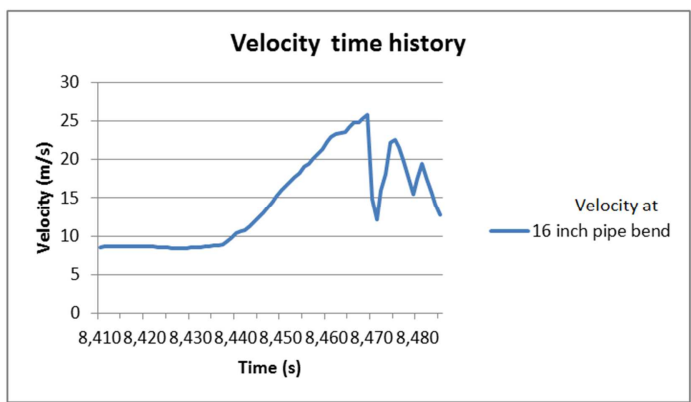

Figure 5. Fluid velocity time history at 16 inch pipe bend.
The forces applied at the bend at all time points are calculated based on the fluid velocity time history. Therefore the load at each bend and tee changes at every second in accordance with the velocity data from the flow assurance analysis.

The 16 inch pipe bend total force time history corresponding to the velocity time history of Figure 5 is shown in Figure 6 as an example. The calculation uses above formula. When the maximum velocity is $25.859 \mathrm{~m} / \mathrm{s}$, the calculated total force is $196303 \mathrm{~N}$ for the 16 inch pipe.

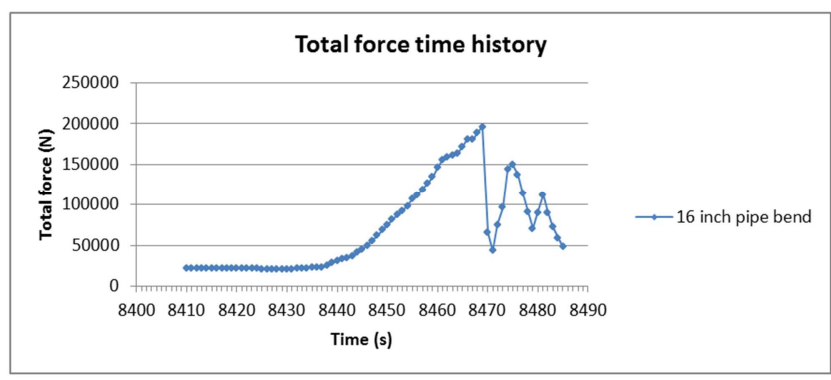

Figure 6. Slug force time history at 16 inch pipe bend.

Table 2 shows the calculated slug force applied at each node of ANSYS FE model. Each node in the first column is related with an elbow or tee of the piping system. Some of the nodes have been marked in Figure 7. For every node (elbow or tee) in Table 2 there is time varying slug flow velocity like Figure 6. Correspondingly each node has time varying slug force calculated from the velocity like Figure 5.

Table 2. Slug Force at Time $=8485 \mathrm{~s}$.

\begin{tabular}{|c|c|c|c|c|c|}
\hline Node Number & OD (in) & Thk (in) & Velocity (m/s) & Total Force (N) & Direction \\
\hline 3193 & 8.65 & 0.5 & 4.61 & 1786.28 & $\mathrm{Fx}, \mathrm{Fz}$ \\
\hline 3185 & 8.65 & 0.5 & 4.16 & 1449.53 & $\mathrm{Fx}, \mathrm{Fz}$ \\
\hline 3177 & 8.65 & 0.5 & 2.67 & 598.42 & $\mathrm{Fx}, \mathrm{Fz}$ \\
\hline 3169 & 8.65 & 0.5 & 3.60 & 1084.17 & Fy, Fz \\
\hline 3161 & 8.65 & 0.5 & 3.94 & 1301.43 & $\mathrm{Fy}, \mathrm{Fz}$ \\
\hline 2128 & 8.65 & 0.5 & 4.20 & 1482.77 & $\mathrm{Fy}, \mathrm{Fz}$ \\
\hline 2138 & 8.65 & 0.5 & 4.61 & 1778.86 & Fx, Fy \\
\hline 1617 & 26 & 1.25 & 3.00 & 7127.56 & $\mathrm{Fx}, \mathrm{Fz}$ \\
\hline 1609 & 26 & 1.25 & 2.36 & 4408.95 & $\mathrm{Fy}, \mathrm{Fz}$ \\
\hline 1603 & 26 & 1.25 & 3.47 & 9517.46 & $\mathrm{Fy}, \mathrm{Fz}$ \\
\hline 1599 & 26 & 1.25 & 4.21 & 14012.22 & $\mathrm{Fy}, \mathrm{Fz}$ \\
\hline 1764 & 26 & 1.25 & 4.26 & 14331.72 & $\mathrm{Fx}, \mathrm{Fz}$ \\
\hline 1677 & 16 & 0.844 & 12.79 & 47984.88 & $\mathrm{Fx}, \mathrm{Fz}$ \\
\hline 1681 & 16 & 0.844 & 9.22 & 24960.29 & $\mathrm{Fx}, \mathrm{Fz}$ \\
\hline 1687 & 16 & 0.844 & 8.66 & 22027.71 & Fx, Fy \\
\hline 589 & 16 & 0.844 & 8.52 & 21327.95 & Fx, Fy \\
\hline 581 & 16 & 0.844 & 8.61 & 21741.30 & Fx, Fy \\
\hline 573 & 16 & 0.844 & 8.66 & 22037.89 & Fx, Fy \\
\hline 138 & 16 & 0.844 & 10.05 & 29627.11 & Fx \\
\hline 549 & 24 & 1.219 & 5.07 & 17115.43 & Fy, Fz \\
\hline 557 & 24 & 1.219 & 5.65 & 21269.73 & $\mathrm{Fy}, \mathrm{Fz}$ \\
\hline 160 & 24 & 1.219 & 2.33 & 3630.42 & Fy \\
\hline
\end{tabular}


The slugging load case has very limited occurrence during pipe operation. In the analysis only dynamic forces due to slugging are considered. Constant loads (e.g. due to pressure and self-weight) are not included for this special case.

The structural damping is assumed to be $1 \%$. The primary effect of the damping is to control the decay of the response after the initial step response. The influence of damping ratio over maximum stress level is negligible.

\subsection{Structural Analysis Results}

Figure 7 shows the maximum von Mises stress (MPa) in the whole piping system within 60 seconds time period.

The extreme value is identified as $207 \mathrm{MPa}$ when time is $50.6 \mathrm{~s}$. Figure 8 is the von Mises stress contour plot at $50.6 \mathrm{~s}$ of the entire system. The location of maximum stress has been marked by a red circle. The stress unit in the contour plots is Pascal instead of MPa. It can be seen that the maximum stress appears at the lower 45 degree elbow of the 16 inch pipe.
Detailed view of stress contour plot for the 16 inch pipe elbow area is shown in Figure 9.

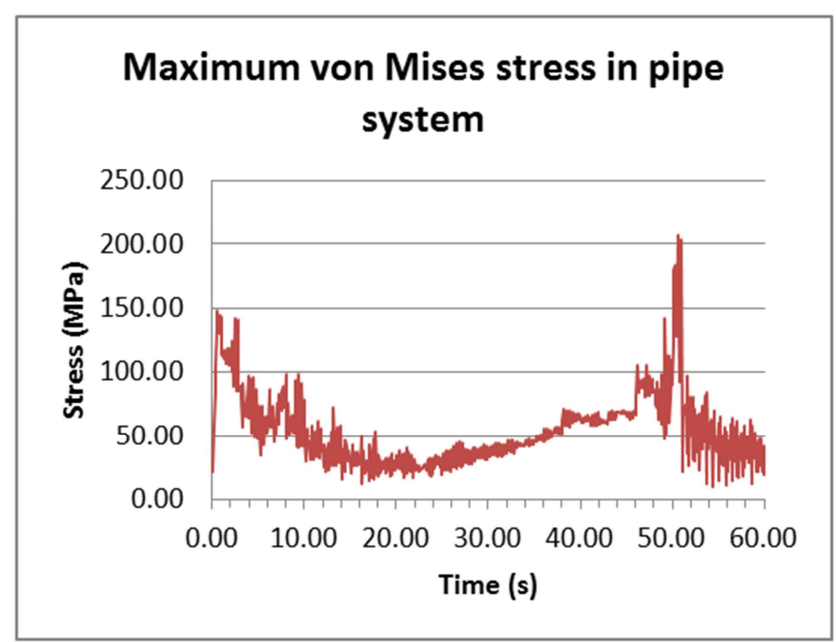

Figure 7. Maximum stress time history.

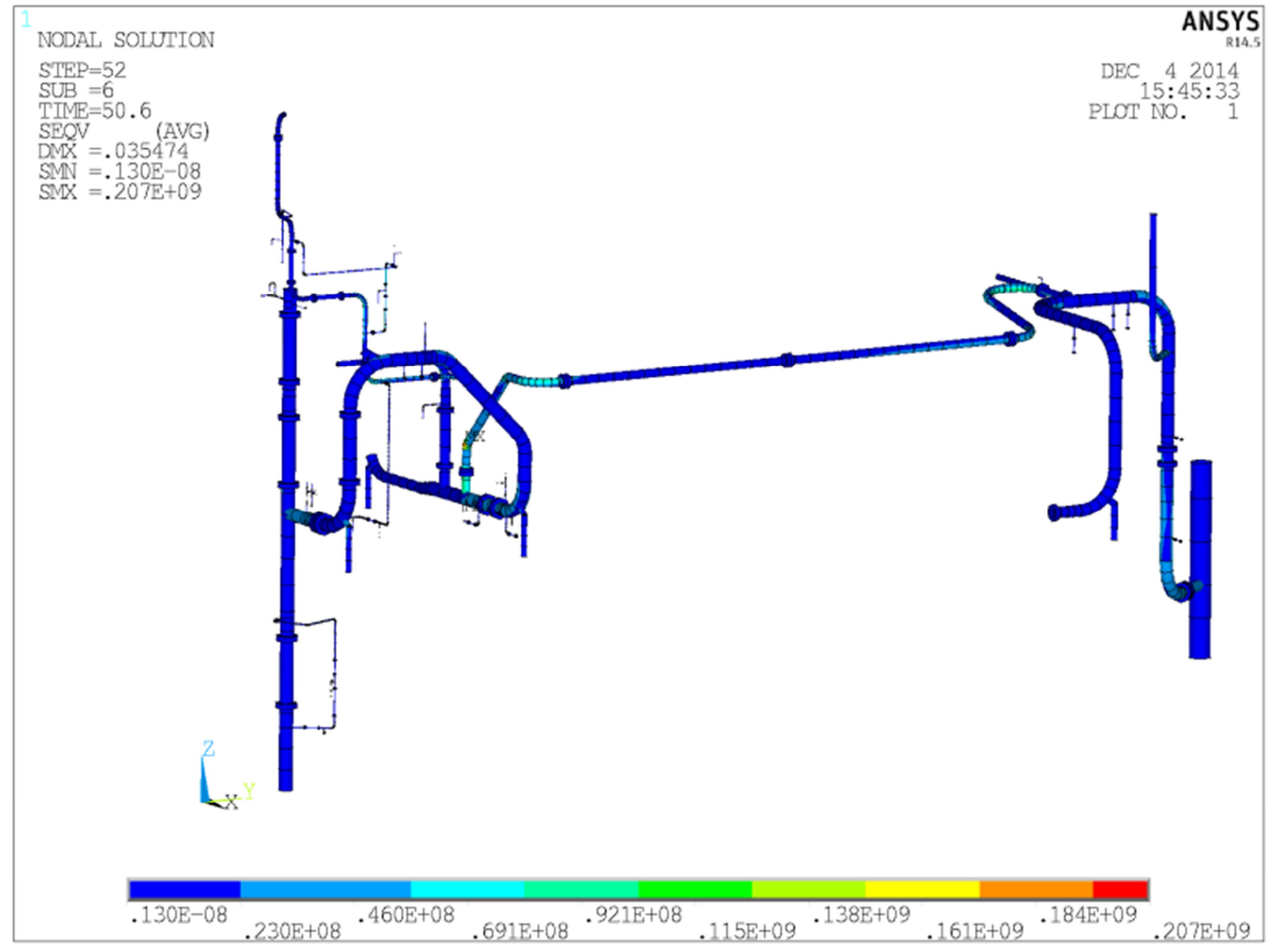

Figure 8. Von Mises stress contour plot with maximum value. 


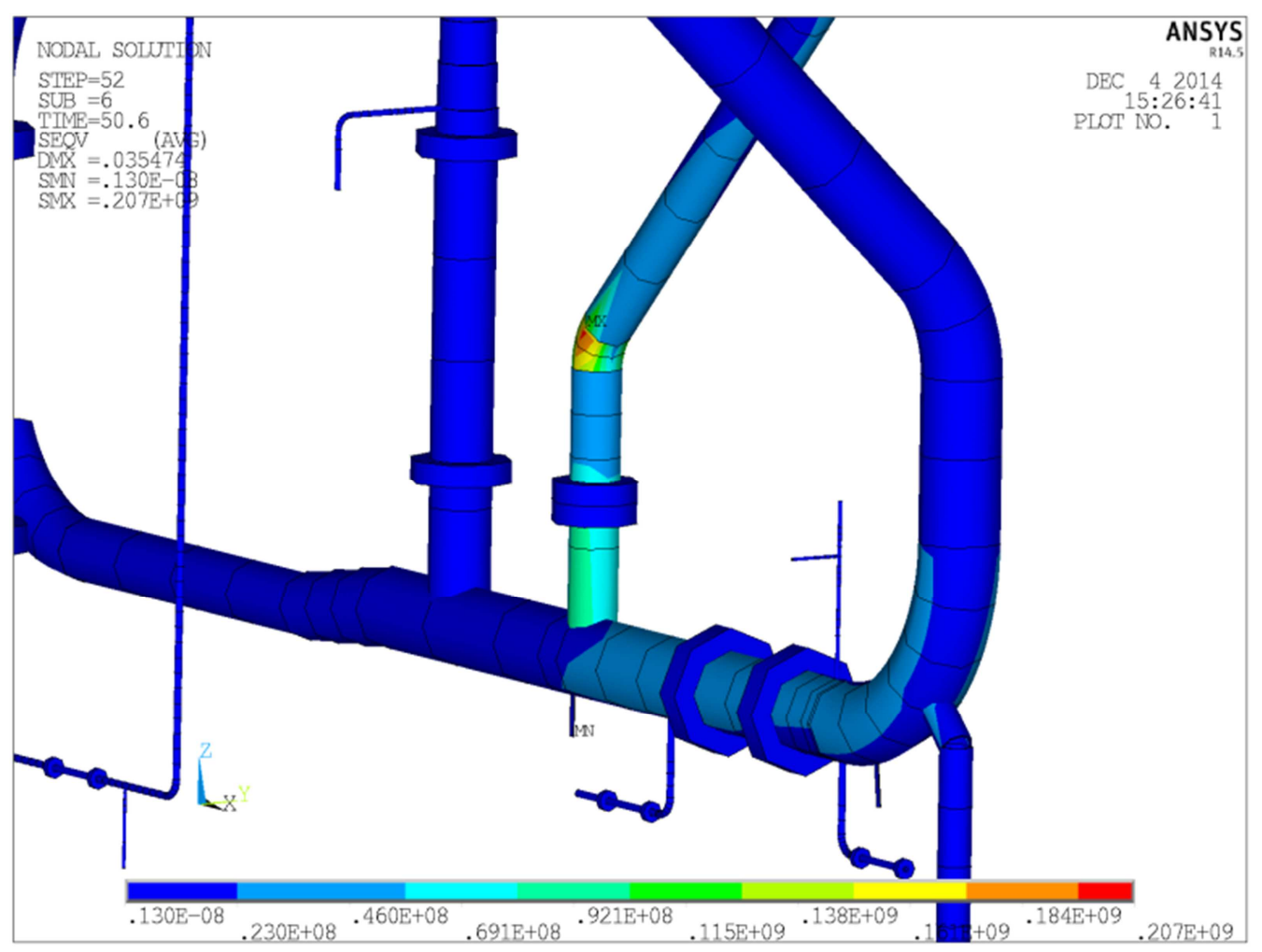

Figure 9. Detailed view of the area with maximum von Mises stress.

Figure 10 shows the time history of the maximum von Mises stress for the two elements at the elbow location in Figure 9.

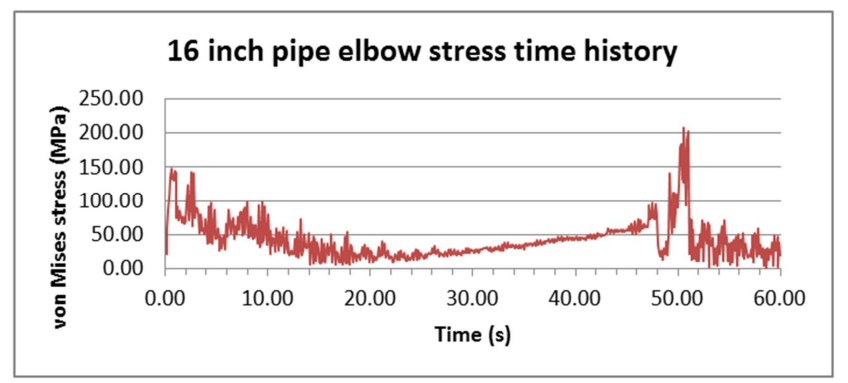

Figure 10. Maximum von Mises stress time history of two bend elements.

It can be seen that stress level at this elbow exceeds the allowable stress $137 \mathrm{MPa}$ at various time points. Therefore necessary modification is needed in order to reduce the stress during pigging process.

Stress contour plots and time history plots of other locations with high stress are listed in the Appendix.

\subsection{Analysis Results After Recommendations}

Based on the analysis results, following measures are recommended in order to reduce the pipe stress due to slugging flow:

- Add North/South direction restraint (5G2 ATTACH N/S) at existing 26 inch elbow support 5G2.

- Add North/South direction restraint (5G2 ATTACH N/S) at existing pipe support 5G1-09 of 16 inch pipe.

Figure 11 shows the maximum von Mises stress in the whole system during 60 seconds period with above the recommended modifications. It can be seen that the stress level is well below allowable stress $137 \mathrm{MPa}$.

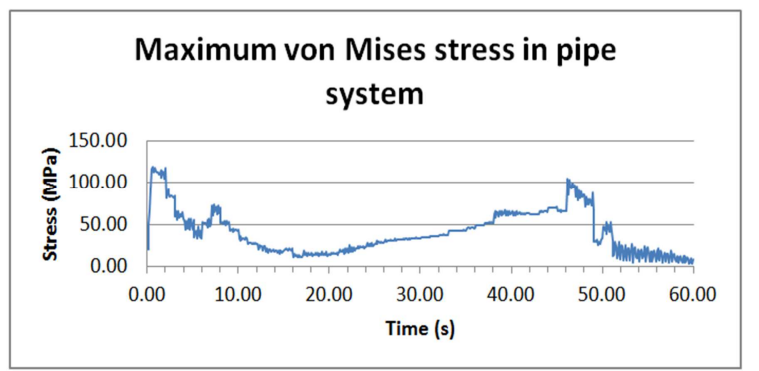

Figure 11. Maximum pipe stress time history with recommended modifications.

\section{Conclusion}

This paper presents the process of the strength analysis of a platform topside piping system during pigging/slugging. The flow assurance analysis by OLGA calculated the velocity history in each pipe. Then the time history of forces was applied at each elbow/bend of the ANSYS structural model. By performing transient analysis, the von Mises stress time history was obtained. The maximum stress of the original design structures has exceeded the allowable limit. Therefore modifications by adding more supports are proposed. With the recommended modifications, the maximum stress of the piping system during pigging/slugging process will be within the limit. 


\section{Appendix}

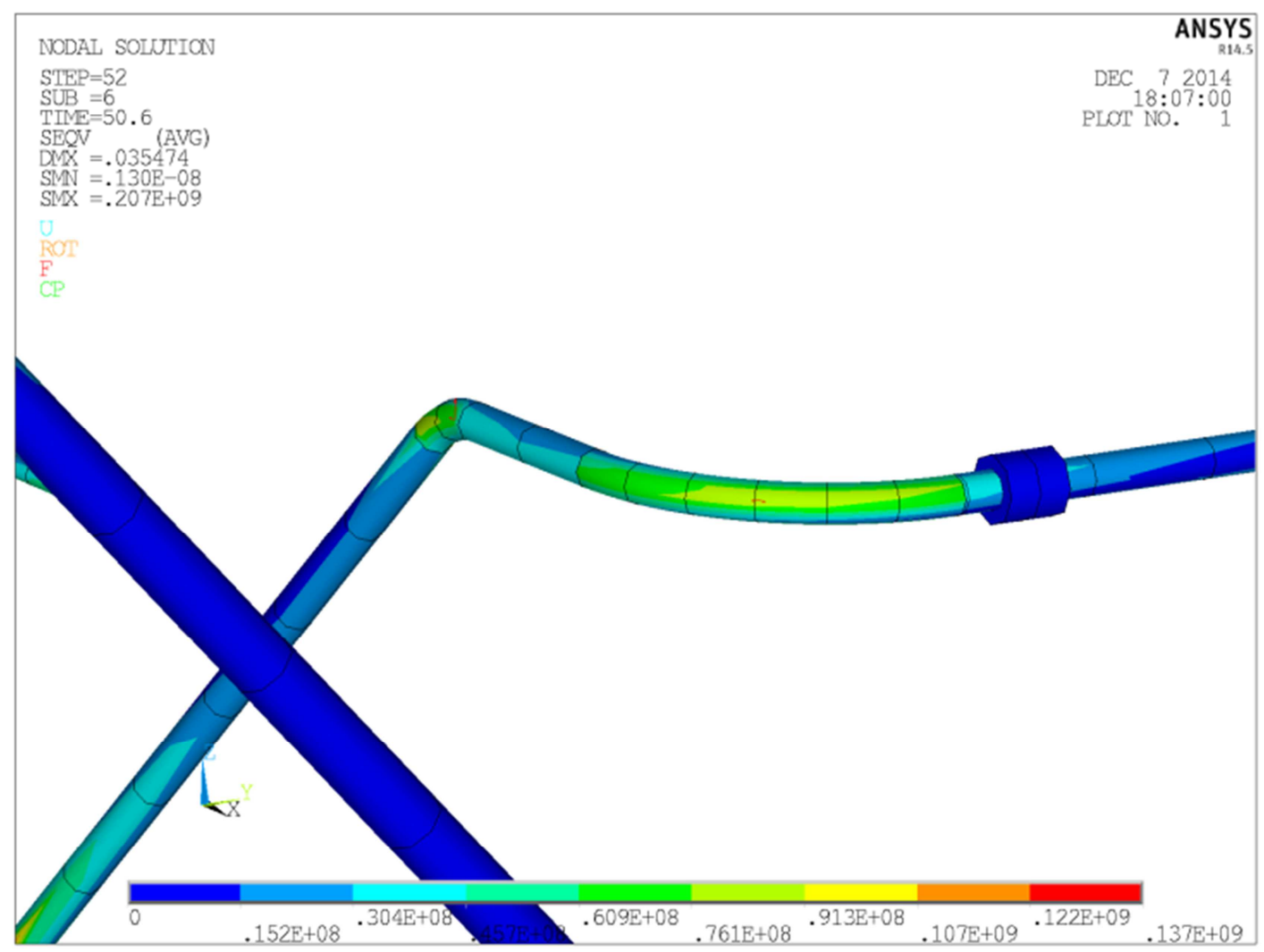

Figure 12. 16 inch pipe von Mises stress.

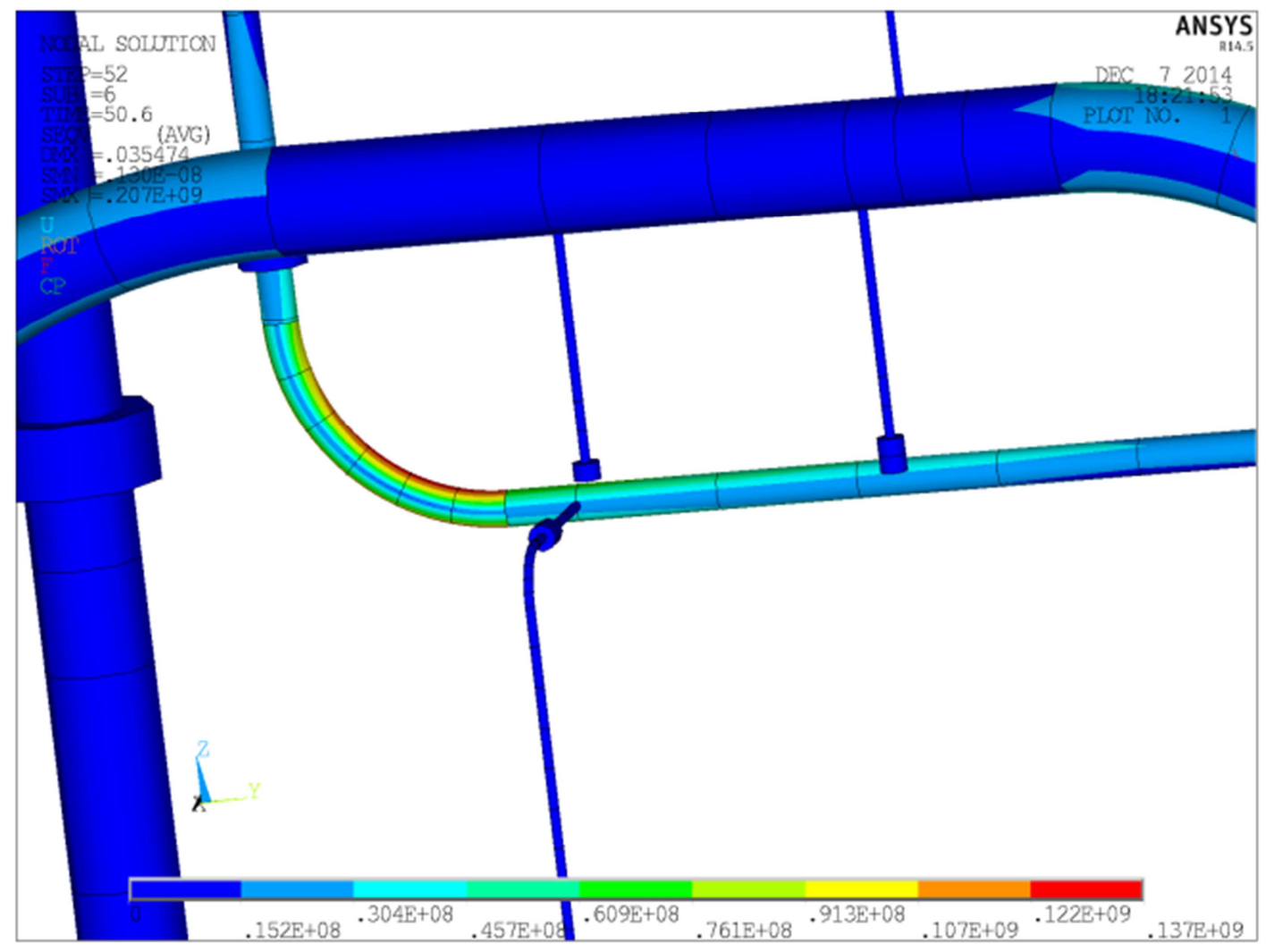

Figure 13. 8 inch pipe von Mises stress. 


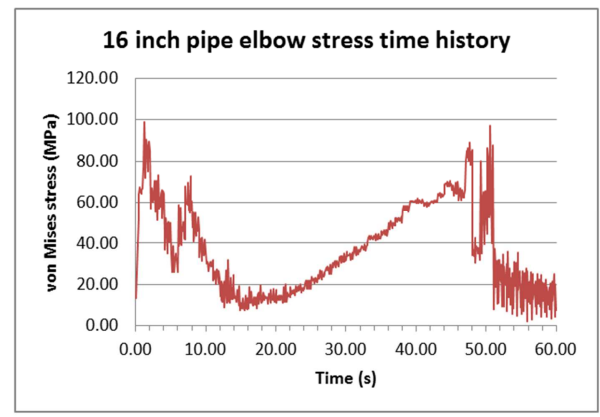

Figure 14. 16 inch pipe elbow stress time history.

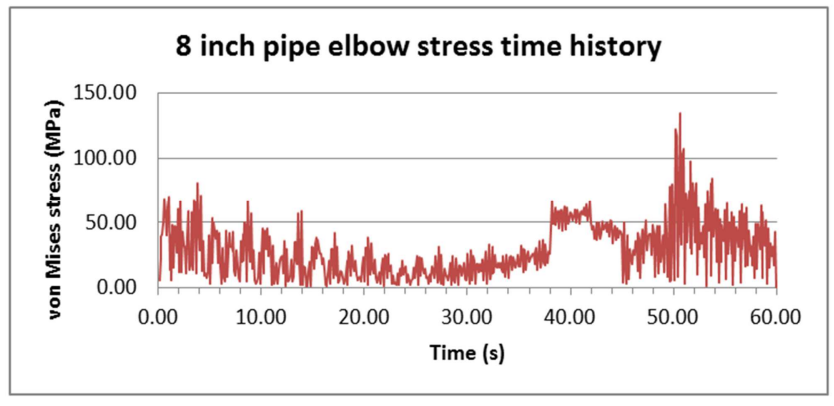

Figure 15. 8 inch pipe elbow stress time history.

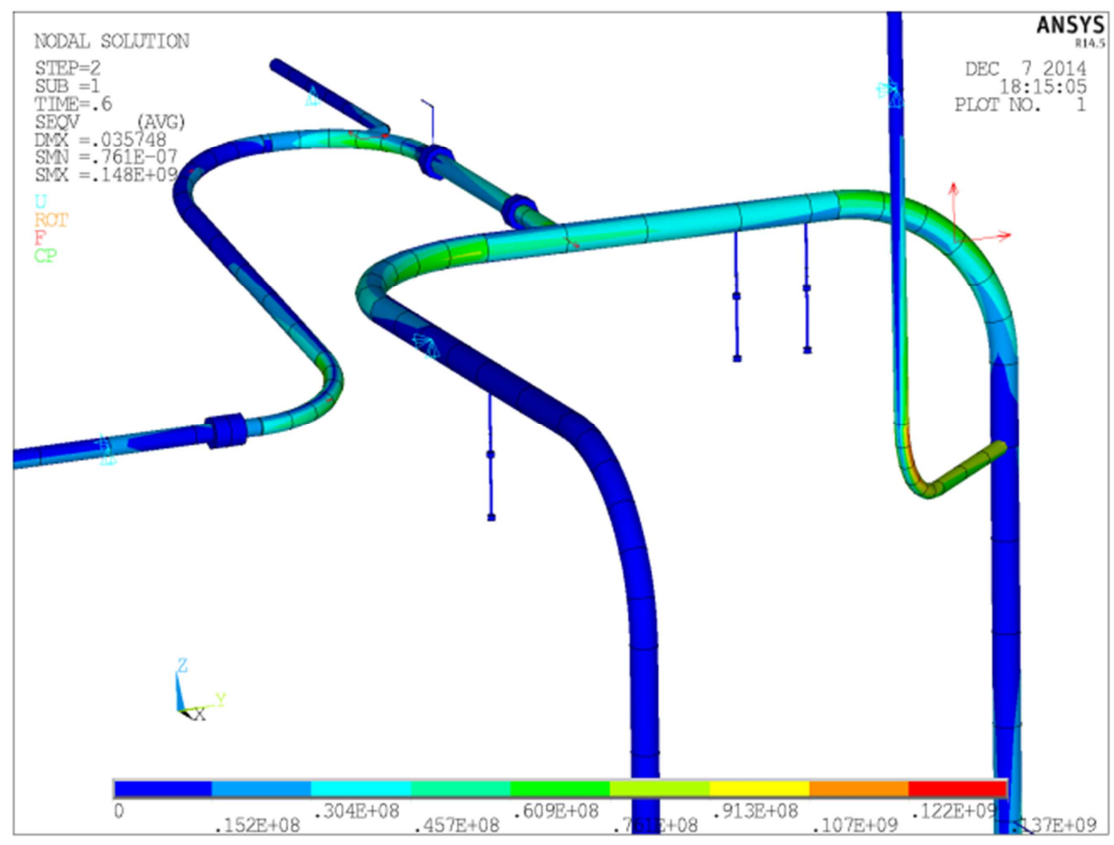

Figure 16. 20 inch pipe von Mises stress.

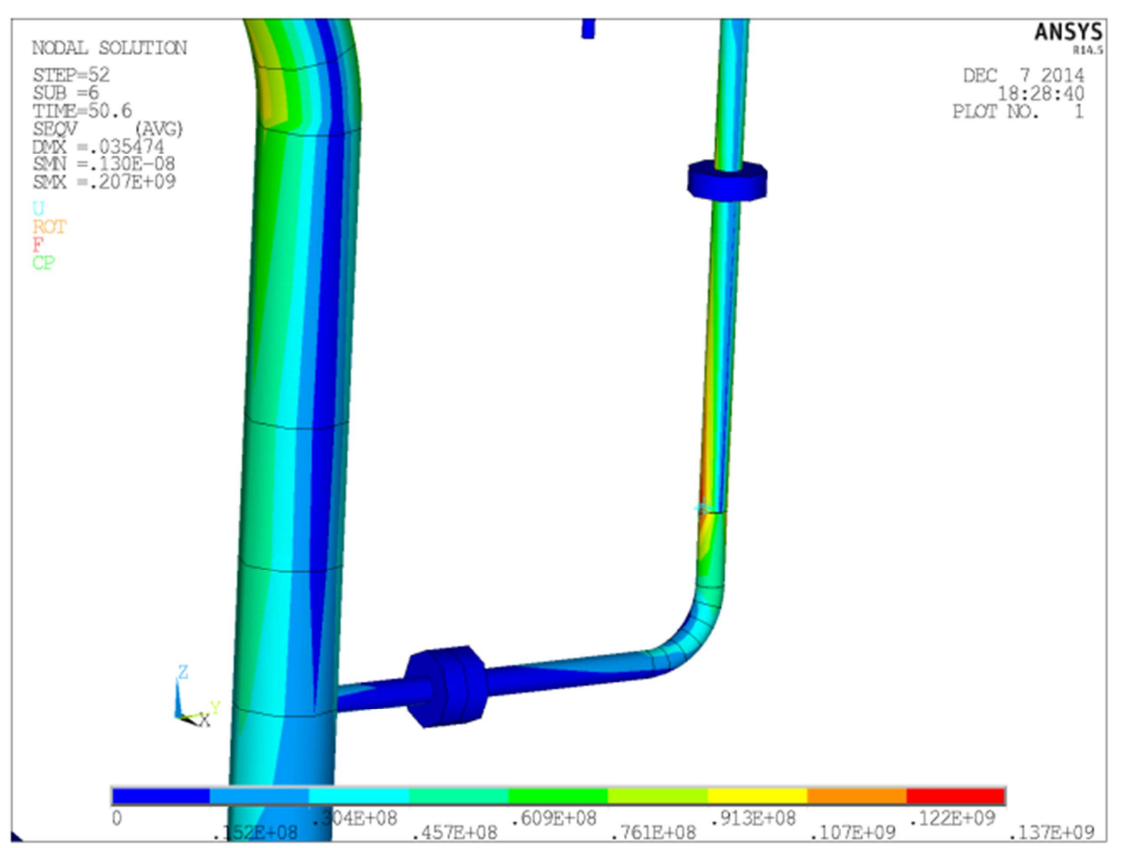

Figure 17. 2 inch pipe von Mises stress. 


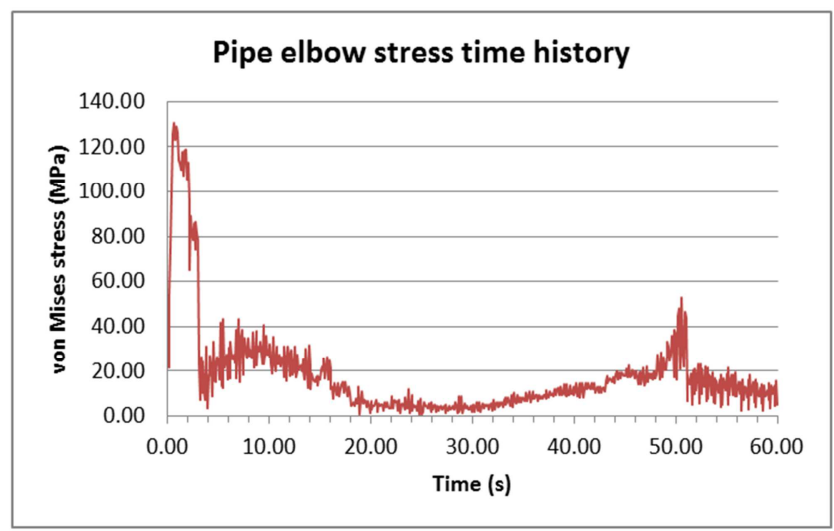

Figure 18. 20 inch pipe elbow stress time history.

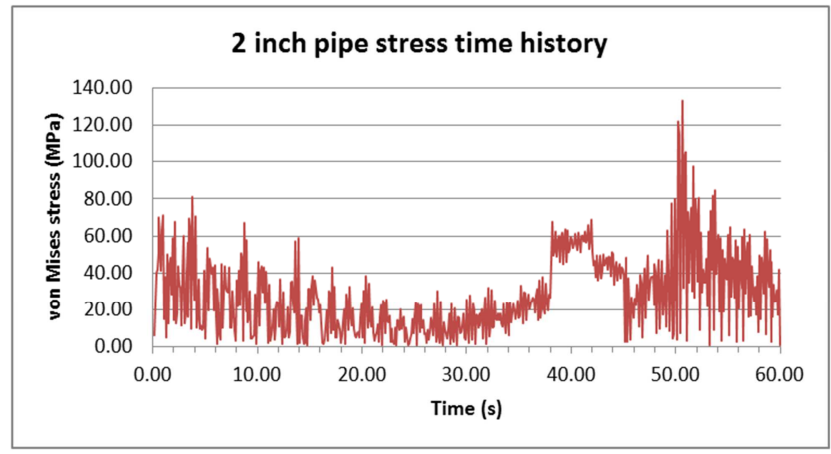

Figure 19. 2 inch pipe elbow stress time history.

\section{References}

[1] ANSYS. User's Manual, Version 15.0, 2013.

[2] ASME, B31.3 Process Piping Design, 2012.

[3] ASME, B31.8 Gas Transmission and Distribution Piping Systems, 2012.

[4] BP, Designing for Multiphase Flow, BP Group Practice 41-20, 2013.

[5] W. Cai, LL. Gouveia. Modeling and Simulation of Maximum Power Point Tracker in Ptolemy. Journal of Clean Energy Technologies, 2013.

[6] J. Cordell, Pipeline Pigging Handbook, $3^{\text {rd }}$ Ed., Clarion Technical Publishers, 2003.

[7] N. Dowling, Mechanical Behavior of Materials, $4^{\text {th }}$ ed., 2012.

[8] J. Gong and W.Z. Wang, Offshore Oil and Gas Mixed Transportation Pipeline Flow Assurance, Science Press: 2016.

[9] J. He, F.G. Yuan. Lamb wave-based subwavelength damage imaging using the DORT-MUSIC technique in metallic plates. Structural Health Monitoring, 2016.
[10] Y. Liu. Nanoscale Thermal Transport at Graphene-Soft Material Interfaces. Doctoral dissertation, Virginia Polytechnic Institute and State University, 2016.

[11] Y. Liu, J. Huang, B. Yang, B.G. Sumpter, R. Qiao. Duality of the interfacial thermal conductance in graphene-based nanocomposites. Carbon, 2014.

[12] A. Maekawa, et al, Development of noncontact measurement methods using multiple laser displacement sensors for bending and torsional vibration stresses in piping systems, International Journal of Pressure Vessels and Piping, v 137, p 38-45, Elsevier, 2014.

[13] E. Naudascher and D. Rockwell, Flow-Induced Vibrations: An Engineering Guide, Dover Publications, 2005.

[14] Oil and Gas Pipeline Flow Assurance Technology, Petroleum Industry Press: 2010.

[15] OLGA User's Manual, Version 7, 2014.

[16] P. Persson, et al., Numerical study of reduction in vibrations induced by water-pipe system, Dynamics of Civil Structures Proceedings of the 33rd IMAC, A Conference and Exposition on Structural Dynamics, 2015.

[17] H. Santos, et al., Development of a simplified methodology for evaluation of piping vibration due to multi-phase flow, ASME 2015 Pressure Vessels and Piping Conference, PVP 2015.

[18] J. Tiratsoo, Pipeline Pigging and Integrity Technology, $4^{\text {th }}$ Ed., Clarion Technical Conferences LLC, 2013.

[19] L. Wang, Y. Ding. Creating micro-structured hydrogel-forming polymer films by photopolymerization in an evaporating solvent: Compositional and morphological evolutions. European Polymer Journal, 2015.

[20] F. Xiao, et al., CFD simulation of vortex-induced vibrations of free span pipelines including pipe-soil interactions, Proceedings of the 25th International Ocean and Polar Engineering Conference, ISOPE 2015.

[21] J. Zhang, J. Gu, L. Li, Y. Huan and B. Wei. Bonding of alumina and metal using bulk metallic glass forming alloy. International Journal of Modern Physics B, 2009.

[22] J. Zhang, J. Johnston, A. Chattopadhyay. Physics-based multiscale damage criterion for fatigue crack prediction in aluminium alloy. Fatigue \& Fracture of Engineering Materials \& Structures, 2014.

[23] J. Zhang, B. Koo, N. Subramanian, Y. Liu, A. Chattopadhyay. An optimized cross-linked network model to simulate the linear elastic material response of a smart polymer. Journal of Intelligent Material Systems and Structures, 2015.

[24] J. Zhang, K. Liu, C. Luo, A. Chattopadhyay. Crack initiation and fatigue life prediction on aluminum lug joints using statistical volume element-based multiscale modeling. Journal of Intelligent Material Systems and Structures, 2013. 